\title{
CHARGED PARTICLE STORAGE DEVICE
}

\author{
Frank Krienen, Boston University
}

\begin{abstract}
This paper deals with the motion of charged particles in a magnetic bottle.

The realization entails an assembly of current loops, which in the present treatment is simplified to three components: a solenoid and two dipoles. For a given configuration of the magnetic field and the initial position and momentum of the particles, it has been found that the particles can be stored in a racetrack-like fashion, looping around at near constant radius, somewhat toe-ing in upon reflection from the repeller at the end of the bottle.
\end{abstract}

\section{EQUATION OF MOTION}

The disposition of the magnetic components is shown in Figure 1 . We identify 4 parameters which determine the magnetic field, namely the distance a of the dipoles to the median plane, the field B of the solenoid and the moments of the upper dipole b' and the lower dipole b".

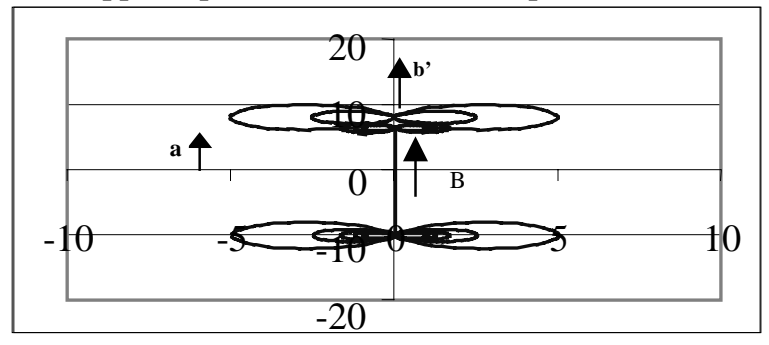

Figure 1: Magnetic Components

A relativistic Hamiltonian which is $\theta$-independent contains only one tangential component $\mathrm{A}$ of the magnetic potential.

$\mathrm{H}=\left[\mathrm{P}_{\mathrm{r}}^{2} * \mathrm{c}^{2}+\left\{\mathrm{P}_{\theta} / \mathrm{r}-\mathrm{e} * \mathrm{~A}\right\}^{2} * \mathrm{c}^{2}+\mathrm{P}_{\mathrm{z}}^{2} * \mathrm{c}^{2}+\mathrm{m}^{2} * \mathrm{c}^{4}\right]^{1 / 2}$

The contribution to $\mathrm{A}$ of a dipole in the origin will be

$\mathbf{A}_{\text {dipole }}=(\mu /(4 * \pi)) * \mathbf{m} \times \nabla(1 / \mathrm{r})_{\text {spherical }}$

where $\mathbf{m}$ is located on the $\mathrm{z}$-axis. We obtain in cylindrical co-ordinates:

$\mathrm{A}_{\text {dipole }}=\left(\mu^{*}|\mathbf{m}| /(4 * \pi)\right) * \mathrm{r} /\left(\mathrm{r}^{2}+\mathrm{z}^{2}\right)^{3 / 2}=\mathrm{b} * \mathrm{r} /\left(\mathrm{r}^{2}+\mathrm{z}^{2}\right)^{3 / 2}$

$\mathrm{b}=\mu^{*}|\mathbf{m}| /\left(4^{*} \pi\right)$

The contribution to $\mathrm{A}$ of a solenoid is $\mathrm{A}_{\mathrm{sol}}=\mathrm{B} *_{\mathrm{r}} / 2$

The contribution to $A$ of the system shown in Fig.1:

$\mathrm{A}=\mathrm{B} * \mathrm{r} / 2+\mathrm{b} * \mathrm{r} /\left[\mathrm{r}^{2}+(\mathrm{z}-\mathrm{a})^{2}\right]^{3 / 2}+\mathrm{b} * \mathrm{r} /\left[\mathrm{r}^{2}+(\mathrm{z}+\mathrm{a})^{2}\right]^{3 / 2}$

$\mathrm{B}_{\mathrm{r}}=-\delta \mathrm{A} / \delta \mathrm{z}=3 * \mathrm{~b} * \mathrm{r} *(\mathrm{z}-\mathrm{a}) /\left[\mathrm{r}^{2}+(\mathrm{z}-\mathrm{a})^{2}\right]^{5 / 2}+$

$+3 * b " * r *(z+a) /\left[r^{2}+(z+a)^{2}\right]^{5 / 2}$

$\delta \mathrm{A} / \delta \mathrm{r}=\mathrm{B} / 2+\mathrm{b} *\left[(\mathrm{z}-\mathrm{a})^{2}-2 * \mathrm{r}^{2}\right] /\left[\mathrm{r}^{2}+(\mathrm{z}-\mathrm{a})^{2}\right]^{5 / 2}$

$+\mathrm{b} * *\left[(\mathrm{z}+\mathrm{a})^{2}-2 * \mathrm{r}^{2}\right] /\left[\mathrm{r}^{2}+(\mathrm{z}+\mathrm{a})^{2}\right]^{5 / 2}$

$\mathrm{B}_{\mathrm{z}}=\mathrm{A} / \mathrm{r}+\delta \mathrm{A} / \delta \mathrm{r}=\mathrm{B}+\mathrm{b} *\left[2 *(\mathrm{z}-\mathrm{a})^{2}-\mathrm{r}^{2}\right] /\left[\mathrm{r}^{2}+(\mathrm{z}-\mathrm{a})^{2}\right]^{5 / 2}$

$+b^{\prime \prime} *\left[2 *(z+a)^{2}-r^{2}\right] /\left[r^{2}+(z+a)^{2}\right]^{5 / 2}$ $\mathrm{dr} / \mathrm{dt}=\delta \mathrm{H} / \delta \mathrm{P}_{\mathrm{r}}=\mathrm{P}_{\mathrm{r}} * \mathrm{c}^{2} / \mathrm{H}$

$\mathrm{d} \theta / \mathrm{dt}=\delta \mathrm{dH} / \delta \mathrm{P}_{\theta}=\left\{\mathrm{P}_{\theta} / \mathrm{r}-\mathrm{e}^{*} \mathrm{~A}\right\} * \mathrm{c}^{2} * \mathrm{r}^{-1} / \mathrm{H}$

$\mathrm{dz} / \mathrm{dt}=\delta \mathrm{H} / \delta \mathrm{z}=\mathrm{Pz} * \mathrm{c}^{2} / \mathrm{H}$

$\mathrm{dP}_{\mathrm{r}} / \mathrm{dt}=\delta \mathrm{H} / \delta \mathrm{r}=\left\{\mathrm{P}_{\theta} / \mathrm{r}-* \mathrm{~A}\right\} *\left\{\mathrm{P}_{\theta} / \mathrm{r}+\mathrm{e}^{*} \mathrm{r}^{*}(\delta \mathrm{A} / \delta \mathrm{r})\right\}^{*} \mathrm{c}^{2} * \mathrm{r}^{1} / \mathrm{H}$

$\mathrm{dP}_{\theta} / \mathrm{dt}=-\delta \mathrm{H} / \delta \theta=0$

$\mathrm{dP}_{\mathrm{z}} / \mathrm{dt}=-\delta \mathrm{H} / \delta \mathrm{z}=\left\{\mathrm{P}_{\theta} / \mathrm{r}-\mathrm{e}^{*} \mathrm{~A}\right\} *\{\mathrm{e} * \mathrm{r} *(\delta \mathrm{A} / \delta \mathrm{z})\}^{*} \mathrm{c}^{2} * \mathrm{r}^{-1} / \mathrm{H}$

substituting (11) in (13) and (15):

$\mathrm{dP}_{\mathrm{r}} / \mathrm{dt}=(\mathrm{d} \theta / \mathrm{dt}) *\left\{\mathrm{P}_{\theta} / \mathrm{r}+\mathrm{e}^{*} \mathrm{r}^{*}(\delta \mathrm{A} / \delta \mathrm{r})\right\}$

$\mathrm{dP}_{\mathrm{z}} / \mathrm{dt}=(\mathrm{d} \theta / \mathrm{dt}) *\left\{\mathrm{e}^{*} \mathrm{r}^{*}(\delta \mathrm{A} / \delta \mathrm{z})\right\}$

\section{MEDIAN PLANE}

\subsection{Parallel Dipoles ( $\left.b^{\prime}=b^{\prime \prime}\right)$}

In the median plane, $\mathrm{z}=0, \mathrm{~B}_{\mathrm{r}}=0$, so that the symmetry is:

$\mathrm{B}_{\mathrm{r}}(\mathrm{r}, \mathrm{z})=-\mathrm{B}_{\mathrm{r}}(\mathrm{r},-\mathrm{z})$ and $\mathrm{B}_{\mathrm{z}}(\mathrm{r}, \mathrm{z})=\mathrm{B}_{\mathrm{z}}(\mathrm{r},-\mathrm{z})$

We will track charged particles which start off the median plane, perpendicular to it and at a given momentum and look for conditions so that the particle is reflected and crosses the median plane again perpendicular to it. In this case the crossing occurs at the same initial radius and momentum but not necessarily at the same $\theta$. This particle continues to be reflected and upon every reflection there will be a constant phase advance $\Delta \theta$, so that the particle seems to meander in space.

If the phase advance per half cycle can be written like $\Delta \theta=\mathrm{k}^{*} \pi / \mathrm{n}, \mathrm{k}$ and $\mathrm{n}$ integer and $\mathrm{k} / \mathrm{n}$ irreducible, the particle track closes upon itself, provided $\mathrm{k}=\mathrm{odd}$, after $2 * \mathrm{n}$ halfcycles. If $\mathrm{k}=$ even, the track collides upon itself after $\mathrm{n}$ half-cycles. Thus for a given configuration (a,b',b", B), we may be able to establish the relation $\left(r, \Delta \theta, p_{t}\right)$, where $p_{t}$ is the total momentum.

The method of calculating the system of first order differential equations, eq.(10) through (15) is that of Runge-Kutta, or its variants. We resort to this method because it is highly unlikely that an analytical solution can be found for the above magnetic field profile -and- if found, highly unlikely that such field can be realized. In fact, we look for an existence proof by trial and error, and consider a successful outcome for $\mathrm{p}_{\mathrm{t}}$ a resonance.

\subsection{Anti-parallel dipoles $\left(b^{\prime}=-b^{\prime}\right)$}

For $\mathrm{B}=0$ : $\mathrm{B}_{\mathrm{r}}(\mathrm{r}, \mathrm{z})=\mathrm{B}_{\mathrm{r}}(\mathrm{r},-\mathrm{z})$ and $\mathrm{B}_{\mathrm{z}}(\mathrm{r}, \mathrm{z})=-\mathrm{B}_{\mathrm{z}}(\mathrm{r},-\mathrm{z})$

Applying the method of 3.1, a resonance shows that the phase advance of the second half cycle changes sign, so 
that the particle follows a closed loop, having the shape of a race track in elongated structures, $(r<<a)$.

\section{SCALING ALGORITHMS}

The solution of a system of first order differential equations, resulting from the expression for $\mathrm{H}$, eq.(1), via the Runge-Kutta method is quite laborious. The following scaling algorithms may alleviate the work.

3.1 Mass-less Particles In the absence of an electric potential, the momentum of the particle determines its path: the mass is irrelevant. Thus one might as well calculate trajectories of mass-less particles having an electronic charge. Such fictitious particles travel with the speed of light, facilitating comparison.

3.2.Momentum Particles with different momentum would have identical trajectories if one scales b',b" and B, but not a, proportionally to the momentum ratio.

3.3 Linear scaling $\lambda$ of the device would scale a given trajectory to the extent that at each corresponding point the radius of curvature is increased by a factor $\lambda$. The solenoid does not scale, $\lambda^{0}$. The dipole field scales as $\lambda^{-3}$, hence we need to scale b' and b" by $\lambda^{3}$ to assure the same magnetic field in corresponding points. It follows that one must scale the momentum by a factor $\lambda^{1}$ to agree with the larger radius of curvature.

3.4 Multiple charged particles would follow the same trajectory if b', b" and B are reduced in the same ratio.

3.5 Phase Advance. All of the above does not affect the phase advance nor any spatial angle in comparable points of either trajectory.

3.6 Scenario Clearly, the above mentioned scenarios may be applied one after the other, ad infinitum.

\section{SOME CONSIDERATIONS}

A solenoidal magnetic field may modulate the phase advance considerably, but, since the effect is predominantly in the region where the particle approaches its apogee, an assembly of circular current loops will have the same outcome. In fact, a concentration of current loops, situated near $\mathrm{z}= \pm \mathrm{a}$ may simulate the above mentioned dipoles, but, computationally, the magnetic potential equation (6) is easier to use.

The apogee of a trajectory is characterized by $\mathrm{P}_{z}=0$, but a resonance requires in addition $\mathrm{P}_{\mathrm{r}}=0$.

With respect to this turning point, the co-ordinates $\mathrm{r}$ and $\mathrm{z}$ are symmetric and the co-ordinates $\mathrm{P}_{\mathrm{r}}, \mathrm{P}_{\mathrm{z}}$ and $\theta$ are antisymmetric, as will be shown in subsequent Figures.

For a given set of parameters $(\mathrm{a}, \mathrm{b}, \mathrm{b}, \mathrm{B}, \mathrm{B})$, resonances turn out to be multi-valued. The simplest pattern seems to be related to the highest momentum and highest penetration into the mirror and may be most useful.
The total momentum vs. the radius follows more or less an inverse square power of $\mathrm{r}$; corrections thereto seem to agree with: $\quad \mathrm{p}_{\text {total }} \propto\left(\mathrm{r}^{-2}+\mathrm{a}^{-2}\right), \quad(\mathrm{r}<\mathrm{a})$

For each iteration, the co-ordinates are fed back into (1), resulting in a chart $\mathrm{dH} / \mathrm{H}$ vs. time. The area above and below the abscissa seems to cancel out fairly well upon crossing the median plane. Fig.2c shows an example.

A Variable Iteration Step is applied, based on the radius of curvature $\mathrm{R}$ and the slope $\alpha$ of each of the co-ordinates: See Fig.2b.The Iteration Step $\propto 1 / \Sigma\left(1 /\left(R^{*} \cos \alpha\right)\right)$

A race track may have adjacent branches moving in opposite direction. This would suggest to fill the bottle with one or more monochromatic particle beams until all branches are filled. If the moving charges remain trapped for measurable and useful time spans, a sudden electro magnetic disturbance could merge adjacent branches, opening a new way to measure cross sections or reaction rates, either nuclear or chemical.

In this respect collisions occur with equal and opposing momentum in the laboratory frame, independent of the mass of the participating species.

The self-magnetic field of multi-prong beams evenly distributed in a circular shell tend to be less than distributions concentrated in only a few branches.

A small value of $\mathrm{B}$ of the solenoid does modulate the kinematics at the apogee appreciable, but the main function of $\mathrm{B}$ is to reduce the spatial divergence of the multi-prong particle beams.

\section{NUMERICAL RESULTS}

The parameters for a trajectory may be written in two arrays: $i)$ the system parameters $\left(\mathrm{a}, \mathrm{b}^{\prime}, \mathrm{b}, \mathrm{B}, \mathrm{e}, \mathrm{m}, \mathrm{c}, \mathrm{H}\right)$ and ii) the initial values $\left(\mathrm{t}, \mathrm{r}, \theta, \mathrm{z}, \mathrm{P}_{\mathrm{r}}, \mathrm{P} \sim \mathrm{P}_{\mathrm{z}}\right)_{\text {intial }}$ We note that $\mathrm{P} \sim=\left(\mathrm{P}_{\theta} / \mathrm{r}-\mathrm{e}^{*} \mathrm{~A}\right)=$ the tangential momentum .

In view of the scaling algorithms, it is sufficient to treat only cases where $m=0$ and e is a single electronic charge. Table 1. Shows the dimension of the system parameters:

Table 1: System Parameters

$\begin{array}{lc}\text { Distance from Dipoles to Median Plane }(\mathrm{m}) & \mathrm{a} \\ \text { Upper Dipole Strength (Tesla*meter } & \mathrm{b} \\ \left.\text { Lower Dipole Strength (Tesla*meter }{ }^{3}\right) & \mathrm{b} \text { " } \\ \text { Solenoid Strength (Tesla) } & \text { B } \\ \text { Light Velocity (m/s) } & \text { c } \\ \text { Total Energy (eV) } & \text { H }\end{array}$

The calculation is best done with dimensionless values. In this respect, the initial array transforms as $\left(\mathrm{t}, \mathrm{r}, \theta, \mathrm{z}, \mathrm{P}_{\mathrm{r}}, \mathrm{P} \sim \mathrm{P}_{\mathrm{z}}\right)_{\text {intital }}=(\mathrm{T}, \mathrm{u}, \mathrm{v}, \mathrm{w}, \mathrm{U}, \mathrm{V} \sim, \mathrm{W})_{\text {initial }}$

The relation between corresponding values is shown in Table 2. 
Table 2: Conversion Ratio

$\begin{array}{llll}\mathrm{T}=\mathrm{t} * \mathrm{c} / \mathrm{a} & \mathrm{u}=\mathrm{r} / \mathrm{a} & \mathrm{v}=\theta /(2 * \pi) & \mathrm{w}=\mathrm{z} / \mathrm{a} \\ \mathrm{U}=\mathrm{c} * \mathrm{P}_{\theta} / \mathrm{H} & \mathrm{V} \sim=\mathrm{c} * \mathrm{P} \sim / \mathrm{H} & \mathrm{W}=\mathrm{c} * \mathrm{P}_{z} / \mathrm{H} & \mathrm{V}=\mathrm{c} * \mathrm{P}_{\theta} /(\mathrm{a} * \mathrm{H})\end{array}$
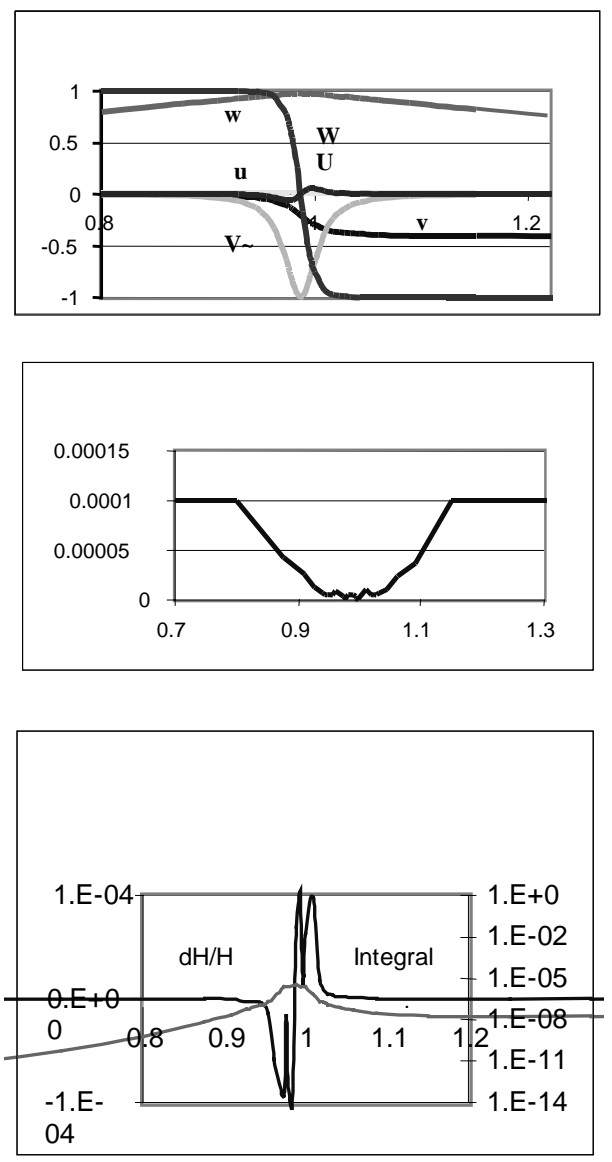

Figure 2 is a 2-Prong Race Track. $(b=-b), u(0)=0.02$ Figure 2a: Co-ordinates vs. Time. Figure 2b: Shows (dT) vs. Time.

Fig.2c: Shows $(\mathrm{dH} / \mathrm{H})$ vs. T, and $f(\mathrm{dH} / \mathrm{H}) \mathrm{dT}$ vs.T $(\mathrm{a}, \mathrm{b}, \mathrm{b}, \mathrm{BH})=(5,5 \mathrm{E}-6,-\mathrm{b}, 0,43720)$.

This case is scaleable for electron cooling of, say, $9 \mathrm{GeV} / \mathrm{c}$ antiprotons that may have a cooling length of $2 * a=30 \mathrm{~m}$ and $\mathrm{H}_{\text {electron }}=4.92 \mathrm{MeV}$

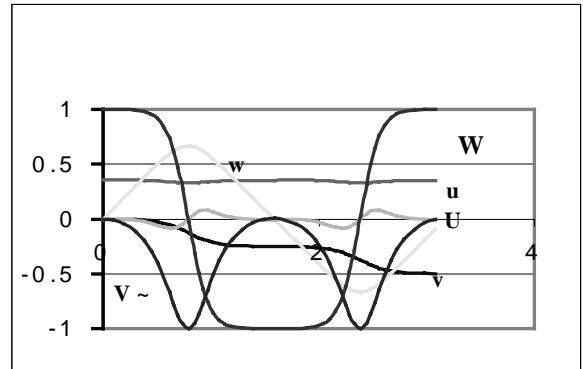

Figure 3 a Coordinates vs. Tim e

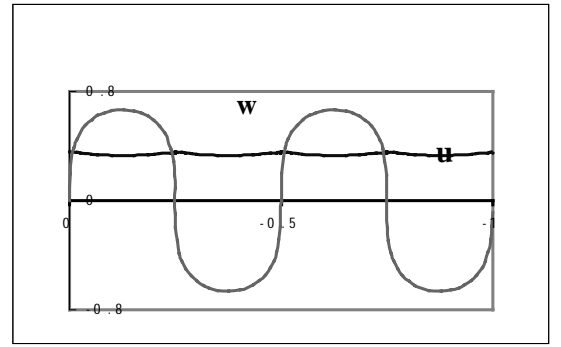

Figure 3 is a Closed 4-Prong Loop $\mathrm{u}(0)=0.0355$

Fig.3a shows $\left(\mathrm{u}, \mathrm{v}, \mathrm{w}, \mathrm{U}, \mathrm{V}_{\iota}, \mathrm{W}\right)$ vs. T. Fig.3b shows $(\mathrm{u}, \mathrm{w})$ vs. v, $(\mathrm{a}, \mathrm{b}, \mathrm{b}, \mathrm{BH})=(0.2,5 \mathrm{E}-6, \mathrm{~b}, 0,98000)$.
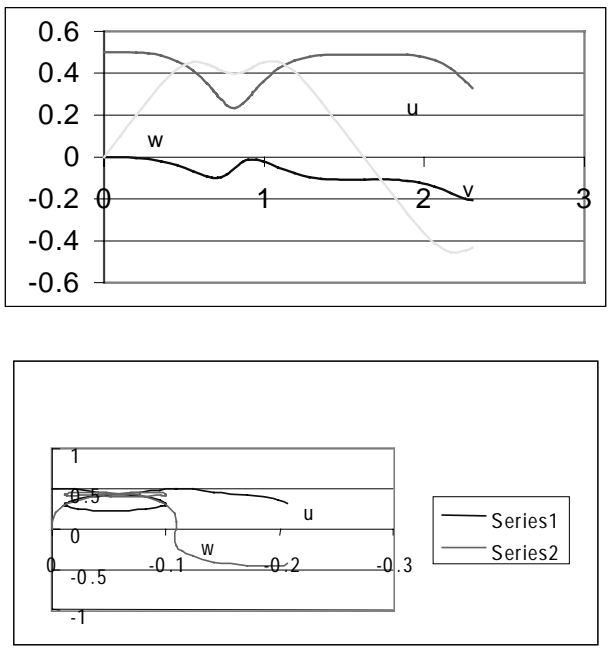

Figure 4 is a Multi-Valued Resonance.

Fig.4a shows $(\mathrm{u}, \mathrm{v}, \mathrm{w})$ vs. T and Fig.4b shows (u,w) vs. v $\mathrm{u}(0)=0.5 \cdot(\mathrm{a}, \mathrm{b} \cdot \mathrm{b}, \mathrm{BH})=(0.2,5 \cdot 2 \mathrm{E}-5, \mathrm{~b}, 1 \mathrm{E}-3,254558)$

\section{DISCUSSION}

No attempt has been made in this paper to devise means to focus stored particle beams. The author conjectures that for short enough time spans, some sort of confinement is possible. For instance the study of cross sections and reaction rates of nuclear or chemical species are head-on, of equal momentum in the laboratory frame, do not need real time and feature independence of the mass of either species.

But in cases of production, such as fuel or chemistry or electron cooling, focusing the beams is of importance. The possibility of organizing the storage in circular shells and/or in several concentric shells, where adjacent beams move in opposition, may alleviate the issue of magnetic pressure or the issue of efficiency or both.

The injection of charged particle beams seems quite feasible: the beams will be bunched in any case and the switching on or off is current practice.

Charge neutrality is again a big issue: the pulsed nature of the device may help to cope with this feature. 